Recibido:

12-IV-2021

Aceptado:

28-VI-2021

Publicado en línea: 15-VII-2021
Trauma oclusal reconstruido con material de fibra reforzada con resina compuesta (FRC)

\section{Occlusal Trauma Restored with a Fiber-Reinforced Composite Resin System (FRC)}

Juan Carlos Ramírez Barrantes DDS, MSD, PhD¹; John Calvo Barillas DDS²

1. Departamento de Ciencias Restaurativas. Facultad de Odontología. Universidad de Costa Rica, Costa Rica.

2. Odontología General. Clínica Privada, Costa Rica.

Autor para correspondencia: Dr. Juan Carlos Ramírez Barrantes - juan.ramirez@ucr.ac.cr

RESUMEN: Las fibras reforzadas con resina compuesta (FRC) son materiales ampliamente utilizados en el área de la ingeniería y la biomedicina. Durante aproximadamente 40 años, vienen siendo investigados demostrando sus excelentes propiedades mecánicas. Desde la perspectiva clínica, se sugieren en diferentes disciplinas de la odontología, donde sus aplicaciones se sustentan con base en los resultados de evidencia científica. Con la introducción de nuevas tecnologías e incorporación de protocolos de adhesión, los materiales fabricados con fibras embebidas en matrices de resina, se recomiendan como subestructuras de soporte. El intento de explorar las propiedades y aplicaciones de los materiales FRC's, en casos clínicos no cotidianos, nos permite brindar una alternativa viable para el planeamiento de tratamientos restauradores.

PALABRAS CLAVES: Biomateriales; Resinas compuestas; Sistemas adhesivos; Dientes fracturados.

ABSTRACT: Fiber-reinforced composite resin systems (FRC) are widely used materials in engineering and biomedicine. For approximately 40 years they have been investigated demonstrating their excellent mechanical properties. From a clinical perspective, they are suggested in different disciplines of dentistry, where their applications are evidenced-based. With the introduction of new technologies and bonding protocols, these types of materials can be used as substructures. The attempt to explore the properties and applications of FRC's materials in non-everyday clinical cases, allows us to provide a viable alternative in the planning of complex restorative treatments.

KEY WORDS: Biomaterials; Composite resins; Adhesive systems; Fractured teeth. 


\section{INTRODUCCIÓN}

Las fibras reforzadas con resina compuesta (FRC) en la disciplina dental vienen siendo desarrolladas y estudiadas desde la década de los 60 's (1), mientras que, los avances en la investigación a principios de los 90's (2-7). Entretanto, el refuerzo incorporado sobre las fibras es estudiado en la literatura, durante más de 40 años (8).

Por su naturaleza, los materiales (FCR's) ofrecen mayor resistencia y rigidez cuando son comparados con otros materiales estructurales, incorporando dentro de sus propiedades la dureza. Estructuralmente, están conformados por tres componentes, la matriz (fase continua), las fibras (fase dispersa) y su zona intermedia (interface). En su fabricación se utilizan filamentos a base de vidrio, carbono, polietileno y poliaramida, entre todos, los confeccionados con fibras de vidrio son seleccionados frecuentemente para restauraciones dentales, siendo a su vez, ampliamente analizados cuando son sometidos a los estudios de laboratorio $(9,10)$.

Los biomateriales FRC's modernos, tienen diversas aplicaciones en la industria de la ingeniería aeroespacial, automovilística y del deporte, donde, su alta resistencia estática y dinámica, como su resistencia a la fractura, especialmente en relación con su peso, siguen siendo las propiedades más deseadas. Están diseñados para obtener mayor eficiencia al utilizarlos como refuerzo, en contraposición a la dirección de las fuerzas a las que se someten, lo que representa normalmente un material anisotrópico en términos de sus propiedades mecánicas (11). Además, otras propiedades como, las ópticas, contracción por polimerización, físico/químicas y térmicas, están relacionadas directamente con la dirección de las fibras incorporadas.
Actualmente, las investigaciones se concentran en las propiedades mecánicas relacionadas a la resistencia compresiva, resistencia a la flexión (12), resistencia a la fatiga (13), resistencia a la fractura (14), capacidad de carga relacionada con la fuerza aplicada (15), 0 en efecto, la espesura del incremento (16) y la adhesión bacteriana relacionada a la configuración estructural (17). Pero quizás la más importante, es aquella donde se estudian diversas aplicaciones dentales orientadas al comportamiento de la adhesión de las fibras con respecto al diseño de las estructuras preestablecidas, como redes (mallas) (18), fibras largas o cortas (19), o rellenos internos dentro de los conductos radiculares, reemplazando eventualmente los postes intrarradiculares convencionales (20). Desde la perspectiva odontológica clínica, los FRC's, siguen siendo utilizados e investigados en la actualidad para diversas aplicaciones en prostodoncia, sobre todo, en el reemplazo de dientes perdidos ubicados como pónticos para prótesis fijas adhesivas (21), estructuras de refuerzo para prótesis removibles (22), o confección directa intrarradicular de postes o núcleos (23). Así, desde el punto de vista de la ciencia de los materiales, representan un grupo de elección para las necesidades dentales y médicas.

La odontología reconstructiva con respecto al tiempo, viene utilizando materiales isotrópicos a granel, como metales, cerámicas, polímeros y resinas compuestas. Así, desde la perspectiva de las ciencias modernas de los materiales, se concluye que la industria mantiene aún el desarrollo muy limitado sobre materiales reconstructivos dentales.

Específicamente, la selección del caso clínico, desarrolla la utilización de materiales FRC's en situaciones menos convencionales, integrando la odontología reconstructiva por trauma, con componentes de hiperoclusión severo para la 
confección de restauraciones convencionales de resina compuesta.

Nuestro objetivo será proporcionar conocimientos de vanguardia en el campo de los materiales FRC's, compartiendo conocimientos básicos de la ciencia de materiales.

\section{CASO CLÍNICO}

Paciente de 27 años, sexo masculino se presentó a la clínica dental con fracturas por trauma dental severo provocado por accidente automovilístico. El examen clínico verificó una condición dental reservada con fracturas múltiples en zona de incisivos superiores, acompañado de un estado periodontal moderado. El examen radiográfico determinó la condición de las fracturas con compromiso pulpar en las piezas dentales 1.1, 2.1 y 2.2 respectivamente. Después del análisis radiográfico, se descartó la presencia de fracturas longitudinales, horizontales o transversales sobre las raíces. Posterior al diagnóstico, se elaboró la referencia para la confección los tratamientos endodónticos de las piezas involucradas por compromiso pulpar y fines restaurativos.

Su queja principal fue, "deseo realizar un tratamiento inmediato con estética aceptable, debido a que no puedo realizarme un tratamiento costoso".

El paciente acepta, mediante la firma de un consentimiento informado que garantiza su anonimidad, la utilización de imágenes y datos clínicos para fines académicos.
En el análisis clínico dental, una semana después de realizados los tratamientos radiculares se comprobó la desfavorable estabilidad oclusal anterior superior e inferior, por mal posición de las piezas dentales (Figura 1. A y B).

De inmediato, por segmentos se valoró la complejidad del trauma, determinando la cantidad de tejido dental remanente para considerar la mejor planificación del tratamiento. Se observó que la pieza dental 2.2 presentaba menor cantidad de tejido dental remanente, involucrando los tercios incisal y medio ausentes (Figura 2. A a C).

Para el análisis oclusal de la zona del trauma, se verificaron las áreas criticas de mayor contacto, corroborando contactos muy cerrados de las superficies palatinas de incisivos superiores contra las superficies incisales de dientes inferiores, en consideración, el canino inferior 3.3 contra la superficie palatina del lateral superior 2.2 (Figura 3. $A$ y B).

Crear técnicas de higiene oral para mejorar las condiciones periodontales serán indispensables al inicio, durante y después de cada tratamiento dental restaurador. Fue compromiso del paciente aceptar el tratamiento y permitir promover su estado de salud bucodental con terapias intensivas de su higiene oral. De esta forma, inicialmente el paciente se sometió a terapias de profilaxis y promoción de la salud bucodental durante 15 días antes del tratamiento, obteniéndose resultados muy satisfactorios para continuar con el plan de tratamiento restaurador elegido (Figura 4). 

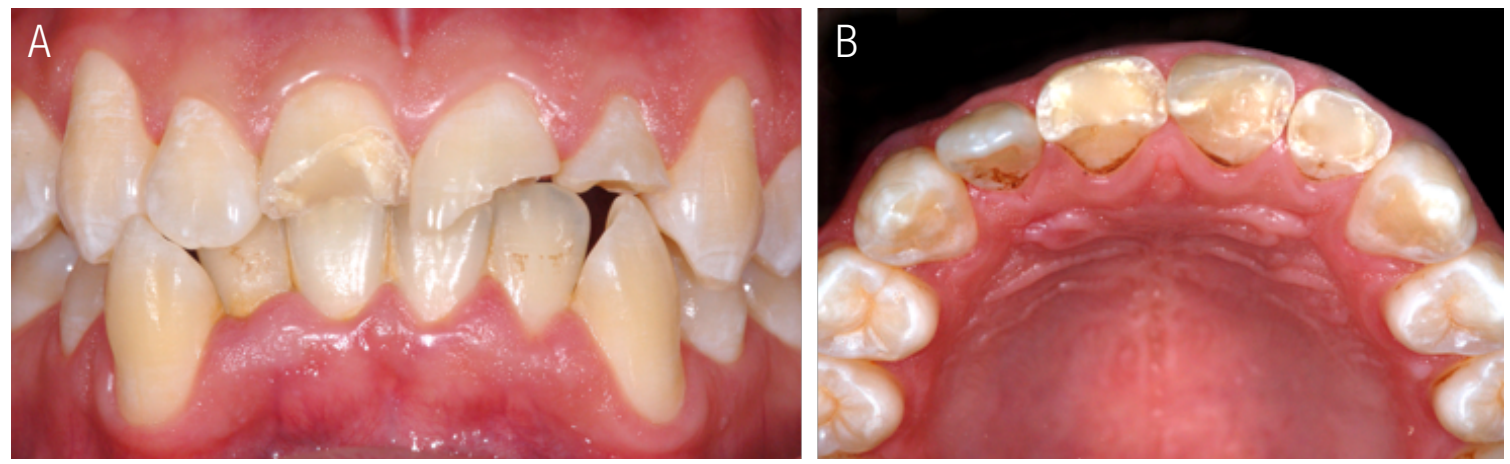

Figura 1. A y B. Vista frontal y oclusal valorando la condición inicial del trauma del paciente. Condición periodontal de gingivitis moderada localizada en sector anterior superior e inferior.
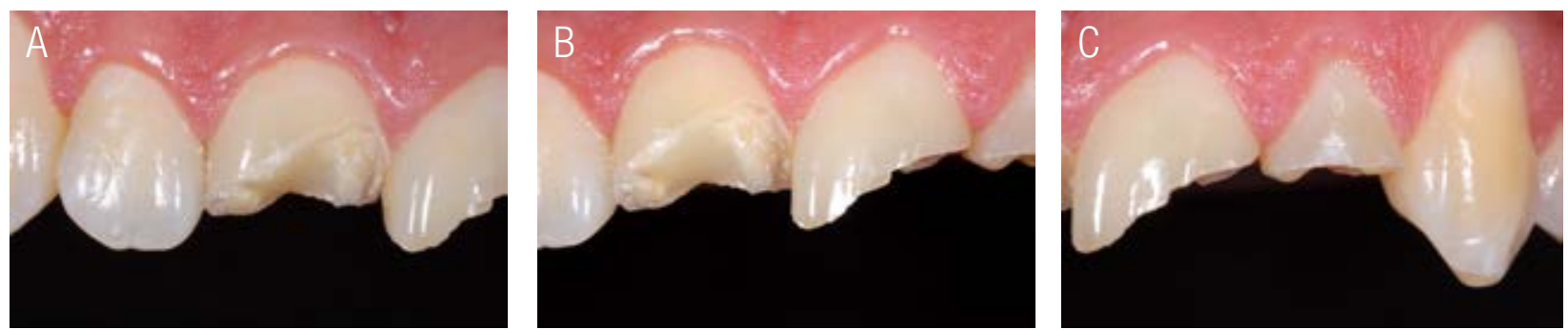

Figura 2. A a C. Vistas frontales valorando los diferentes grados de fractura presentes en relación a la cantidad de tejido dental remanente sano.
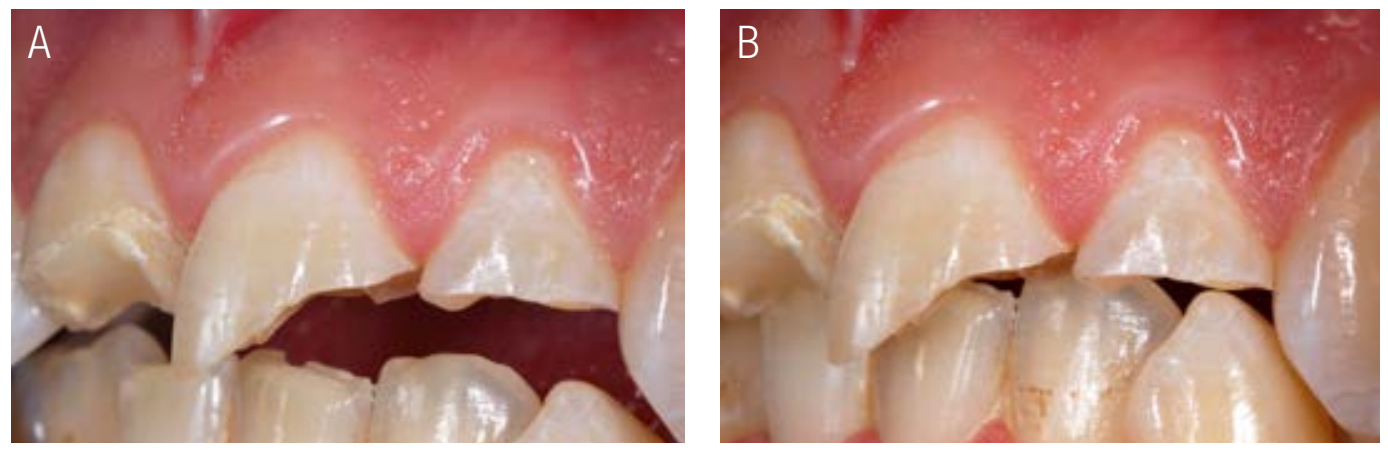

Figura 3. A y B. Vista lateral del plano incisal en apertura y cierre, verificando la inestabilidad en el área de posición de mordida de contactos sobre relación céntrica.

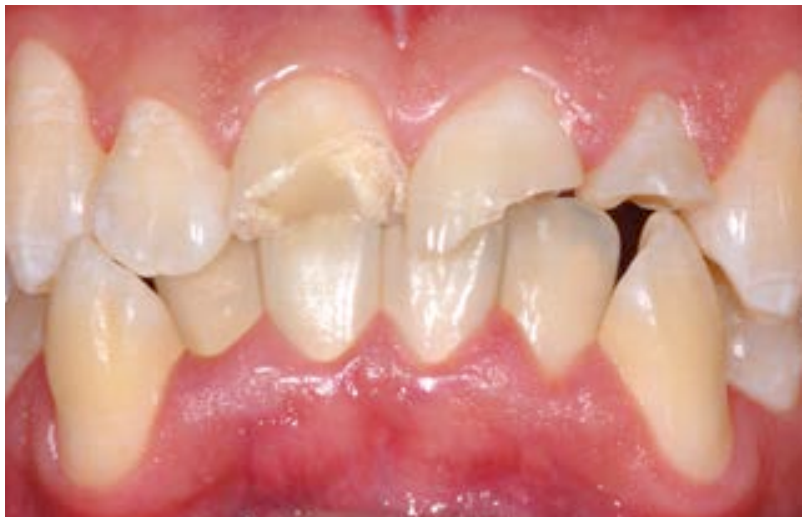

Figura 4. Vista frontal en oclusión del sector anterior. En acercamiento se observa la condición periodontal aceptable del paciente después de la terapia intensiva de promoción de la salud bucodental. 


\section{PLAN DEL TRATAMIENTO RESTAURADOR}

En el análisis clínico previo a realizar el plan del tratamiento, la condición inicial de las piezas dentales tratadas endodónticamente se observaban restauradas con resina compuesta, sin invadir el margen circunferencial comprendido por esmalte.

Por consiguiente, en el análisis biomecánico de las superficies vestibulares, se determinó que la pieza dental más afectada era la 2.2, con extensión mesio distal de fractura horizontal en el tercio cervical, desde vestibular hasta palatino. Ninguna de las fracturas de los dientes involucrados 1.1, 2.1 y 2.2 en su extensión comprometían el periodonto. Tampoco existía en ninguna, la presencia de micro fracturas de esmalte adicionales, pero si áreas de contacto que indicaban cargas oclusales fuertes durante la oclusión y masticación, siendo este punto, el más relevante para elegir cual sería el tipo y forma de restauración confeccionada.

En relación a la estabilidad oclusal del paciente, se establecieron los puntos de contacto en las superficies palatinas e incisales inicialmente, especialmente en la piezas dentales donde se rehabilitaría con restauraciones. Se controlaron todos los aspectos oclusales de análisis de fuerzas y carga sobre las piezas dentales. Se prestó atención a la musculatura del paciente, las actividades funcionales $y / 0$ parafuncionales, la intensidad y la dirección de las fuerzas, la ubicación y fuerza de los puntos de contacto, como también los contactos sobre sus superficies.

Posteriormente, fueron valoradas las radiografías de control periapicales y de aleta de los tratamientos endodónticos, correspondientes a las piezas dentales comprometidas, sin visualizar ninguna alteración periapical.
Después del montaje adecuado de los modelos de estudio en el respectivo articulador, fueron valorados los siguientes aspectos transferidos, Ios cuales formaron parte del análisis minucioso realizado por los profesionales. En relación a la estabilidad oclusal del paciente fueron analizados los puntos de contacto de las superficies oclusales, en condición estática y dinámica con registros de oclusión en máxima intercuspidación y relación céntrica, determinando a su vez, el análisis funcional de guía canina, sobre todo y específicamente para verificar las superficies involucradas de las piezas dentales donde se rehabilitaría.

Instantáneamente, la información se transcribió a un esquema de diseño de diagrama en papel, anotando las áreas de contacto existentes. También se observaron otros factores como desgastes dentales diferenciados por origen mecánico o biocorrosivo sobre los bordes incisales de los dientes anteriores inferiores, no así, grados de destrucción dental severos, desajustes 0 extensión de restauraciones en las demás piezas dentales. Otro análisis desfavorable que cobró importancia fue, la valoración de la proporción de los dientes que debían ser restaurados, en particular, por la longitud real no existente debido a la fractura, muy necesaria para restaurar de manera armónica y estética los dientes. Por esta razón se tomó como punto de referencia el lateral superior derecho 1.2, el cual fue la única pieza intacta después de sufrir el trauma, siendo este referencia para realizar un excelente encerado de diagnóstico. Por lo demás, existía una inclinación axial inadecuada con incorrecta posición de la línea media, aumentando el perfil labial, con extensión y relación de sobremordida horizontal (overjet) muy cerrada y sobremordida vertical (overbite) al menos de la pieza dental 1.2 de $2 \mathrm{~mm}$. Muchos de estos factores fueron corroborados por, el examen intraoral, los hallazgos clínicos, historial 
del paciente, radiografías, fotografías y modelos yeso, dentro del análisis completo de la condición actualizada del paciente.

Cuando se realizaron los tratamientos endodónticos, se procuró trabajar con el mayor cuidado posible, esto, para preservar estructuralmente la mayor cantidad de tejido de esmalte sano, además, ser muy selectivos, para no adherir componentes sobre el área del esmalte en el reborde periférico y así, no cubrirlo ni contaminarlo con resina compuesta o soluciones utilizadas para la adhesión, esto con la finalidad de preservar una zona limpia, con alto potencial de adhesión para la restauración final. De esta manera, se logró obtener una condición final totalmente intacta de la superficie de esmalte, pero con un selle perfecto en toda la apertura confeccionada para el tratamiento endodóntico, previniendo por protocolo, su eventual contaminación (Figura 5).

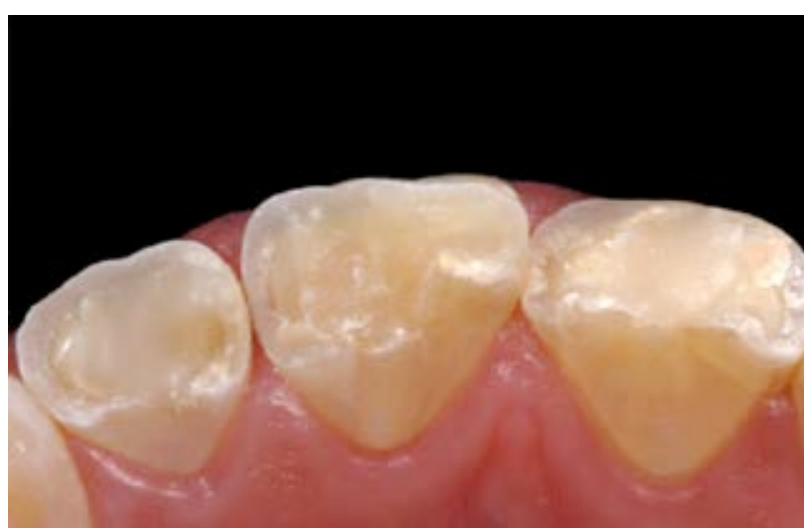

Figura 5. Observe en la fotografía el cuidado utilizado para preservar el tejido de esmalte intacto, sin la aplicación y adherencia de resina compuesta.

Inicialmente para el trabajo de laboratorio fue confeccionado el encerado diagnóstico. A partir del mismo, se fabricó la guía de silicona copiando fielmente las superficies palatinas de los incisivos superiores anatómicamente encerados. Es importante destacar que al realizar el encerado diagnóstico, siempre debe confeccionarse aditivamente sobreextendiendo la cera, obteniéndose dimensiones en las superficies aún mayores, sobre todo, en los bordes incisales e interproximales para permitir que, al confeccionar la resina compuesta y realizar los procedimientos de acabado y pulido, puedan ser contorneados o disminuidos para obtener la anatomía estética más favorable, acorde con las dimensiones finales requeridas.

El encerado diagnóstico es un instrumento necesario en la planificación del resultado final del tratamiento, desde la perspectiva de la dinámica funcional y estética periférica, obteniéndose el mejor resultado final.

Para iniciar el protocolo de los procedimientos clínicos, la guía de silicona fue posicionada y acoplada correctamente después de recortarla, para comprobar posteriormente su ajuste sobre la piezas dentales fracturadas.

Una vez ajustada la guía de silicona, se procedió a realizar la selección del color con los dientes debidamente hidratados, colocando incrementos de resina compuesta en la superficie vestibular y en los tercios existentes de cada uno de los dientes fracturados. De esta forma, conseguimos realizar el mapeo del color natural de los dientes en los respectivos tercios dentales (Figura 6. A y B).

Al iniciar del protocolo restaurador se realizó el aislamiento relativo del campo operatorio, eligiendo utilizar la cinta de teflón en las piezas dentales adyacentes, reforzando adicionalmente con la guía de silicona, como ayuda para mantener una barrera individualizada de aislamiento relativo (Figura 7). 

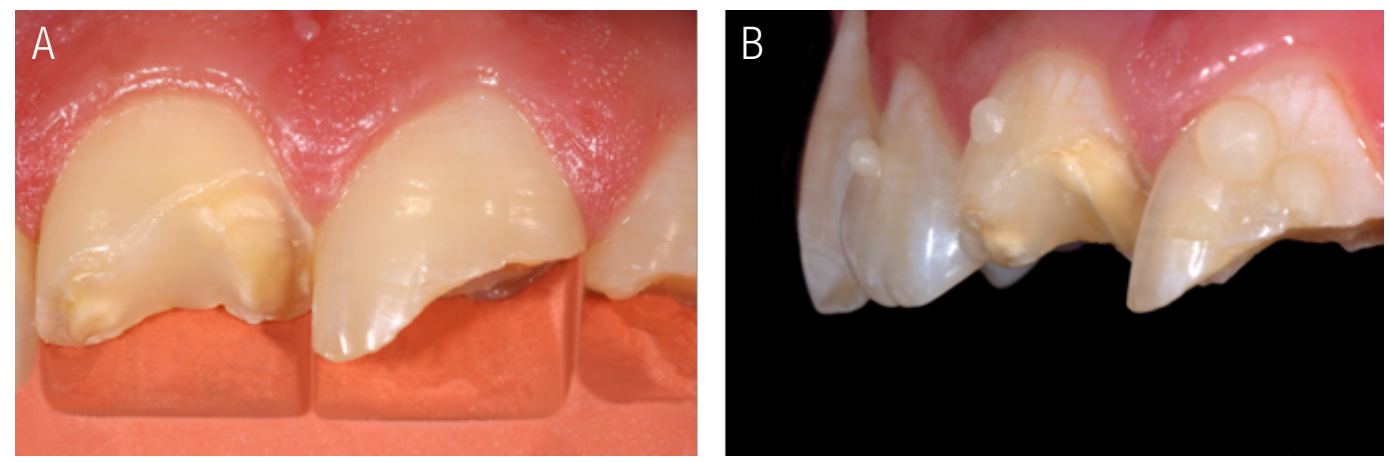

Figura 6. A y B. El ajuste de la guía de silicona es importante antes de iniciar los procedimientos del tratamiento, como también se observa en la fotografía la selección del color inicialmente con los dientes totalmente hidratados.

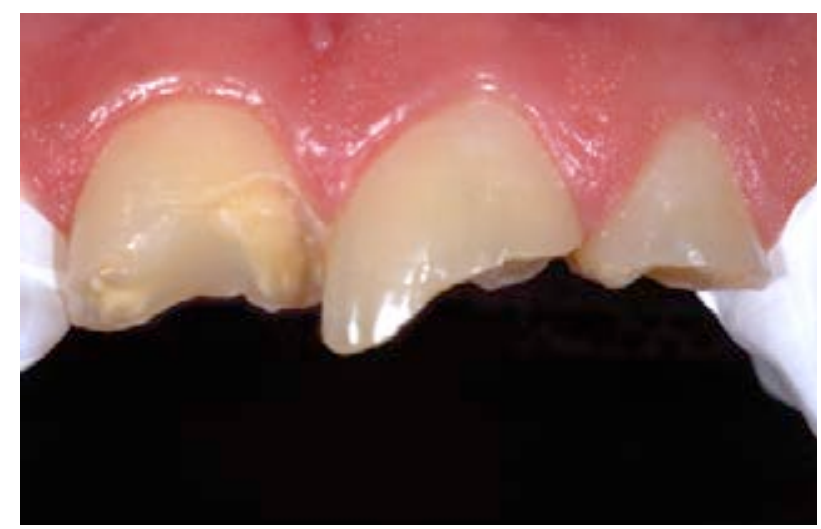

Figura 7. El aislamiento relativo secuencial en la piezas vecinas es de suma importancia al restaurar las piezas dentales elegidas. Obsérvese la cinta de teflón bien adaptada protegiendo y aislando de los componentes de adhesión a las piezas no involucradas.

\section{PROTOCOLO ADHESIVO}

Con el tejido de esmalte listo para ser grabado sin presencia de impurezas, se procedió a iniciar con el protocolo de adhesión, quizá lo más importante, utilizando un sistema adhesivo de tres pasos.

La adhesión se define como el mecanismo que une dos materiales en íntimo contacto, a través de una interface (24). El adhesivo es el material que une dos sustratos solidificándose para transferir carga de una superficie a la otra (25). Los conceptos generales a partir de uniones adhesivas indican que las propiedades físico-mecánicas de los adherentes y adhesivos como, el módulo elasticidad, expansión térmica y contracción por polimerización son importantes para el éxito a largo plazo de las mismas (26).

La vinculación de la adhesión en la odontología restauradora, es el resultado de diferentes mecanismos determinados por, la adhesión mecánica, que implica la penetración de la resina en las irregularidades del diente 0 materiales de restauración, por medio de un entrabamiento en el interior de las irregularidades, la unión química, que existe entre el adhesivo y el adherente, como, la unión química al componente inorgánico de la hidroxiapatita o componentes orgánicos principalmente colágeno tipo I de la estructura del diente, y por último, la presencia de la adhesión por difusión, que involucra el entrelazado entre moléculas, como, la adhesión polímero-polímero a 
través de la difusión de los extremos de la cadena del polímero por medio de una interface.

Después de realizar el aislamiento relativo, se aplicó el sistema adhesivo de tres pasos, colocando inicialmente ácido fosfórico al 37\% en toda la superficie interna fracturada además de, sobreextenderlo sobre la superficie vestibular aproximadamente $2 \mathrm{~mm}$ a partir del borde cavosuperficial, esto con la finalidad de desvanecer los componentes del sistema adhesivo como, la resina compuesta con la ayuda de pinceles personalizados (Figura 8. A y B).

Después de eliminar copiosamente el ácido fosfórico al 37\%, se procedió a colocar el sistema adhesivo respetando el protocolo establecido por el fabricante, para conseguir la adecuada adhesión (Figura 9. A a D).

Posteriormente, el sistema adhesivo fue fotopolimerizado (Figura 10. A y B).
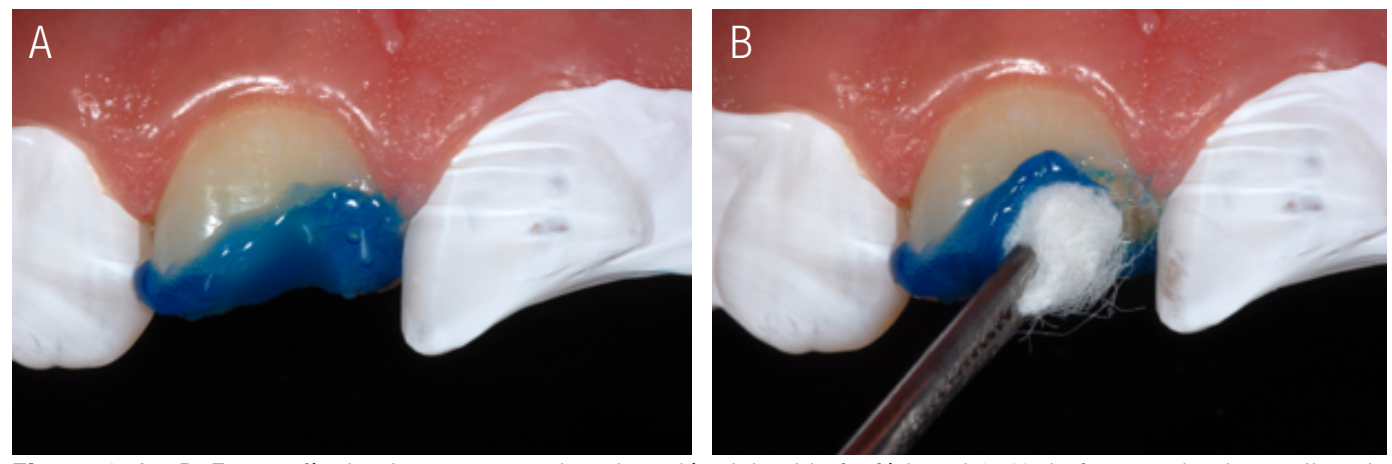

Figura 8. A y B. Fotografía donde se muestra la colocación del acido fosfórico al 37\% de forma selectiva realizando la sobreextensión en vestibular de $2 \mathrm{~mm}$ a partir del borde cavosuperficial.
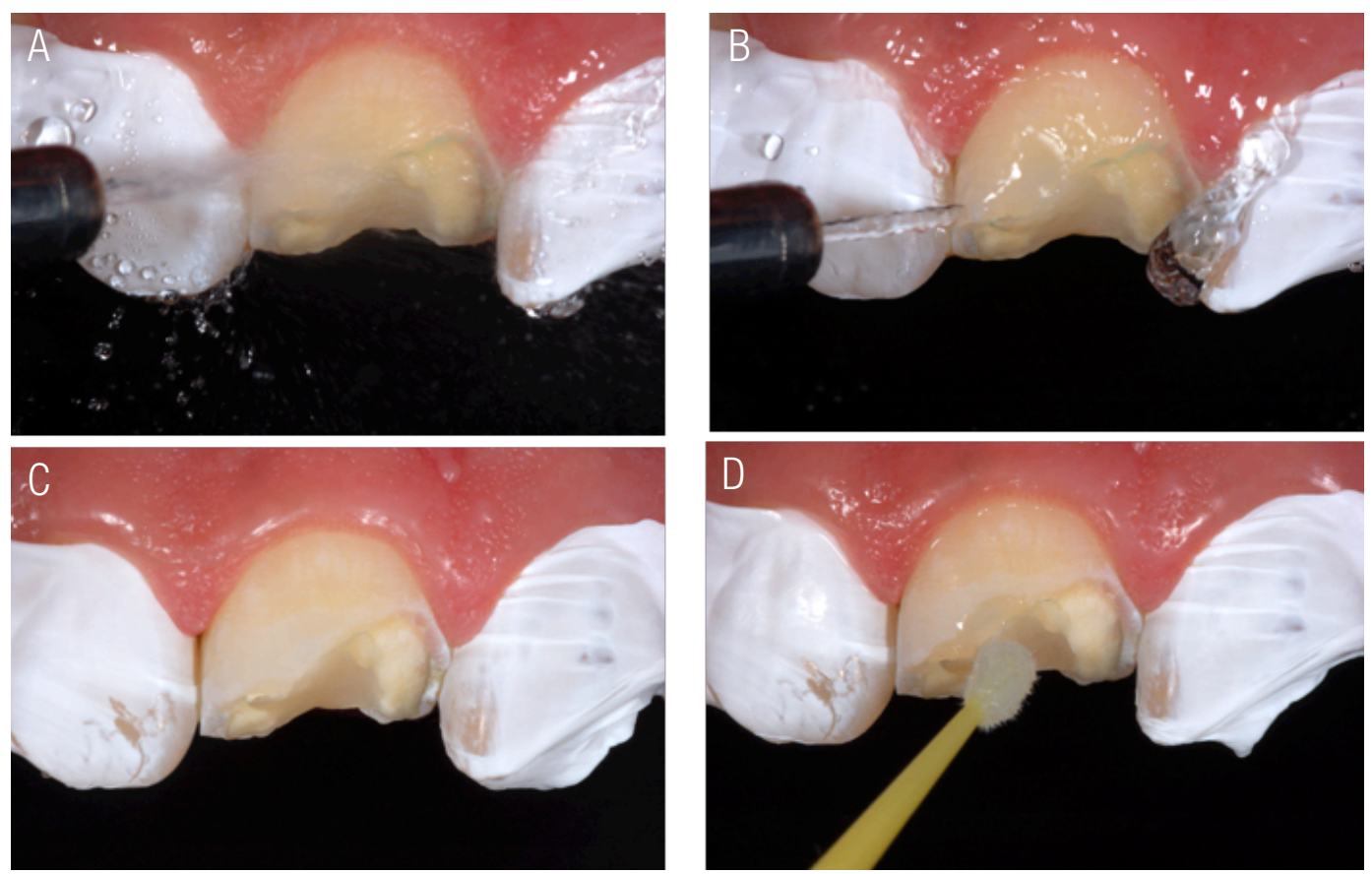

Figura 9. A a D. Lavado copioso del ácido fosfórico al 37\% para preparar la superficie donde serán aplicados los componentes del sistema adhesivo. Obsérvese la sobrextensión del grabado ácido del esmalte en la superficie vestibular (9C). 

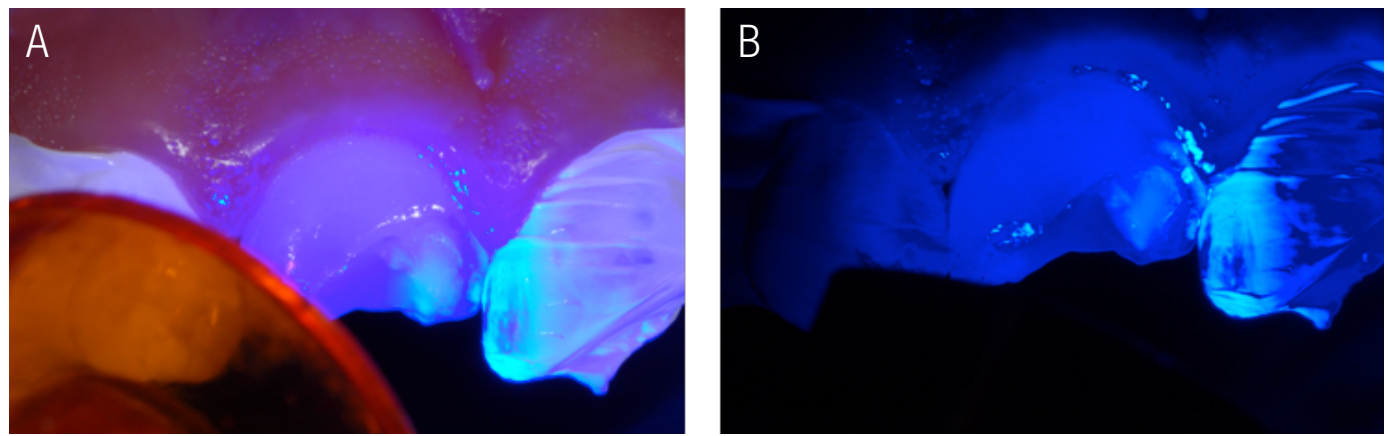

Figura 10. A y B. Fotopolimerización bajo la calibración adecuada de intensidad de la fuente de luz.

APLICACIÓN DEL MATERIAL FRC

Una de las aplicaciones más prometedoras de los FRC's es su utilización para la fabricación de prótesis parciales fijas (FPD) de puentes adhesivos u onlay's. Dichas restauraciones se componen de 2 tipos de material de resina, una subestructura de fibras reforzada con resina compuesta y otra confeccionada como recubrimiento, por sobreposición de la resina compuesta convencional (27).

Las prótesis parciales fijas o restauraciones de piezas unitarias de FRC's pueden retenerse de la superficie del substrato $(28,29)$ y/o retenerse de una pieza protésica (30), como también, no requerir de ninguna o solamente de una preparación mínimamente invasiva. Además, pueden fabricarse directa 0 indirectamente a un menor costo presentando una estética mejorada.

Por lo tanto, las prótesis parciales fijas 0 prótesis unitarias fijas de FRC's representan una alternativa viable de tratamiento (31). Sin embargo, existe poca evidencia clínica a corto plazo para respaldar la utilización de FRC's en prótesis parciales fijas o reconstrucciones unitarias. De tal forma, en este caso clínico específico se decidió utilizar material FCR como complemento, para aumentar aún más, la resistencia de la restauración de resina compuesta CIV convencional, debido a la complejidad de la oclusión existente.
Inicialmente, el materia FRC fue colocado sobre la superficie de la guía de silicona, y a la vez, esparcido con finos movimientos desde la superficie mesial hacia distal, esto con la ayuda del pincel. El esparcimiento cubrió toda la superficie palatina comprendida en la guía de silicona, seguidamente y con un instrumento bruñidor de huevo, se orientaron los filamentos de modo que se alinearan lo más paralelos posibles entre sí (Figura 11).

La guía de silicona fue acoplada contra las piezas dentales, simultáneamente realizando presión constante y verificando que las fibras estuvieran en contacto íntimo con el substrato del diente. Con un instrumento de resina plano bien fino, reorientamos cualquier filamento de fibra que no estuviera en posición de forma paralela y correcta, esto para adaptarlas y así acoplarlas de la mejor forma a la superficie de la guía de silicona.

Una vez orientado el material FCR, se procedió a fijarlo con un incremento de resina compuesta, distribuyéndolo entre la unión de las fibras y el borde cabo superficial interno de la superficie palatina, verificando su continuidad. Posteriormente, fue realizada la fotopolimerización del incremento de resina compuesta extendido desde mesial a distal (Figura 12. A a D).

Al retirar la guía de silicona, la subestructura de FRC actuará como soporte para recibir los 
incrementos de resina compuesta y restaurar las piezas dentales. A partir de este procedimiento la confección de la restauración esta determinada a respetar los protocolos establecidos para un restauración CIV convencional con resina compuesta (Figura 13).

Realizamos posteriormente una resina compuesta CIV convencional, sin olvidar los cuidados necesarios para obtener una restauración de alta gama estética con funcionalidad reforzada.

La aplicación del color fue elaborado con respecto a los colores de resinas compuestas anteriormente seleccionadas. La inserción de los incrementos se realizaron uno a uno, con espesuras de aproximadamente $2 \mathrm{~mm}$ y fotopolimerizados, y a la vez, desvanecidos con la ayuda de pinceles personalizados en cada una de las aplicaciones.

Es importante recalcar que los desvanecimientos permitieron obtener la mimetización de las resinas compuestas, obteniendo el resultado de los colores de manera aún mas natural. Los detalles internos anatómicos de los tres mamelones fueron confeccionados respetando el espacio entre la distancia mesiodistal, con su respectivo color seleccionado para la dentina y colores translúcidos ámbar, azul y naranja, ubicados en cada una de las zonas específicas para obtener un excelente resultado final, con estética natural (Figura 14. A a F) (Figura 15. A a F).

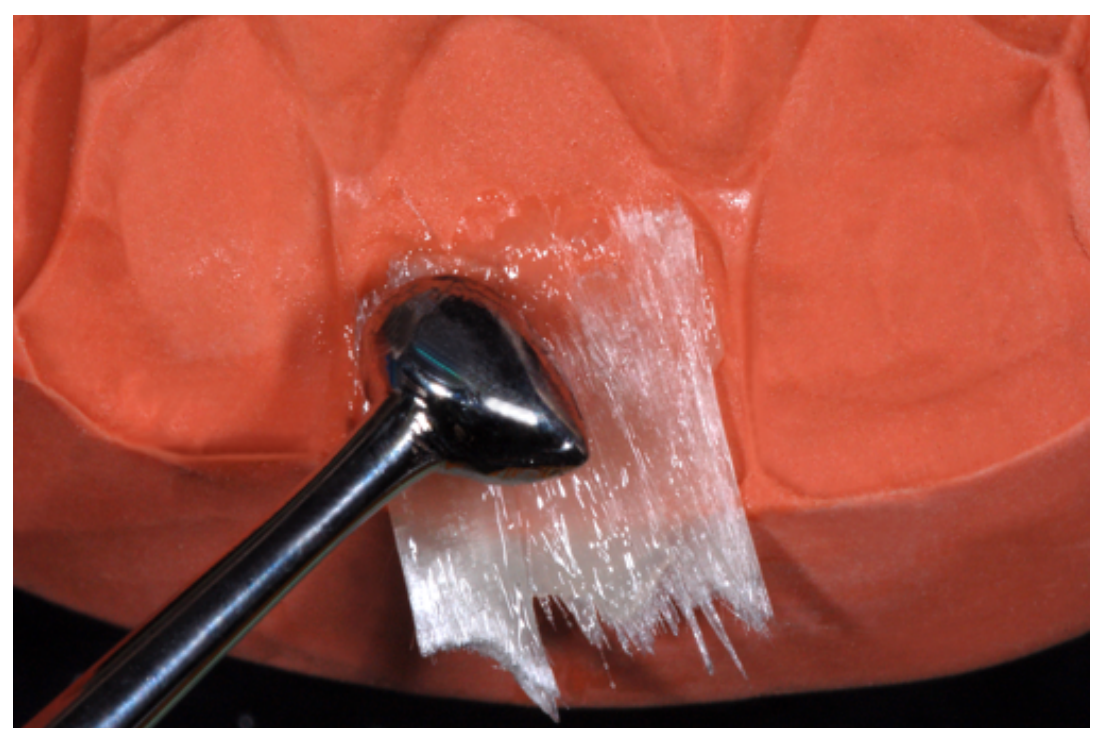

Figura 11. Se observa la colocación y distribución del material FRC sobre la guía de silicona. 

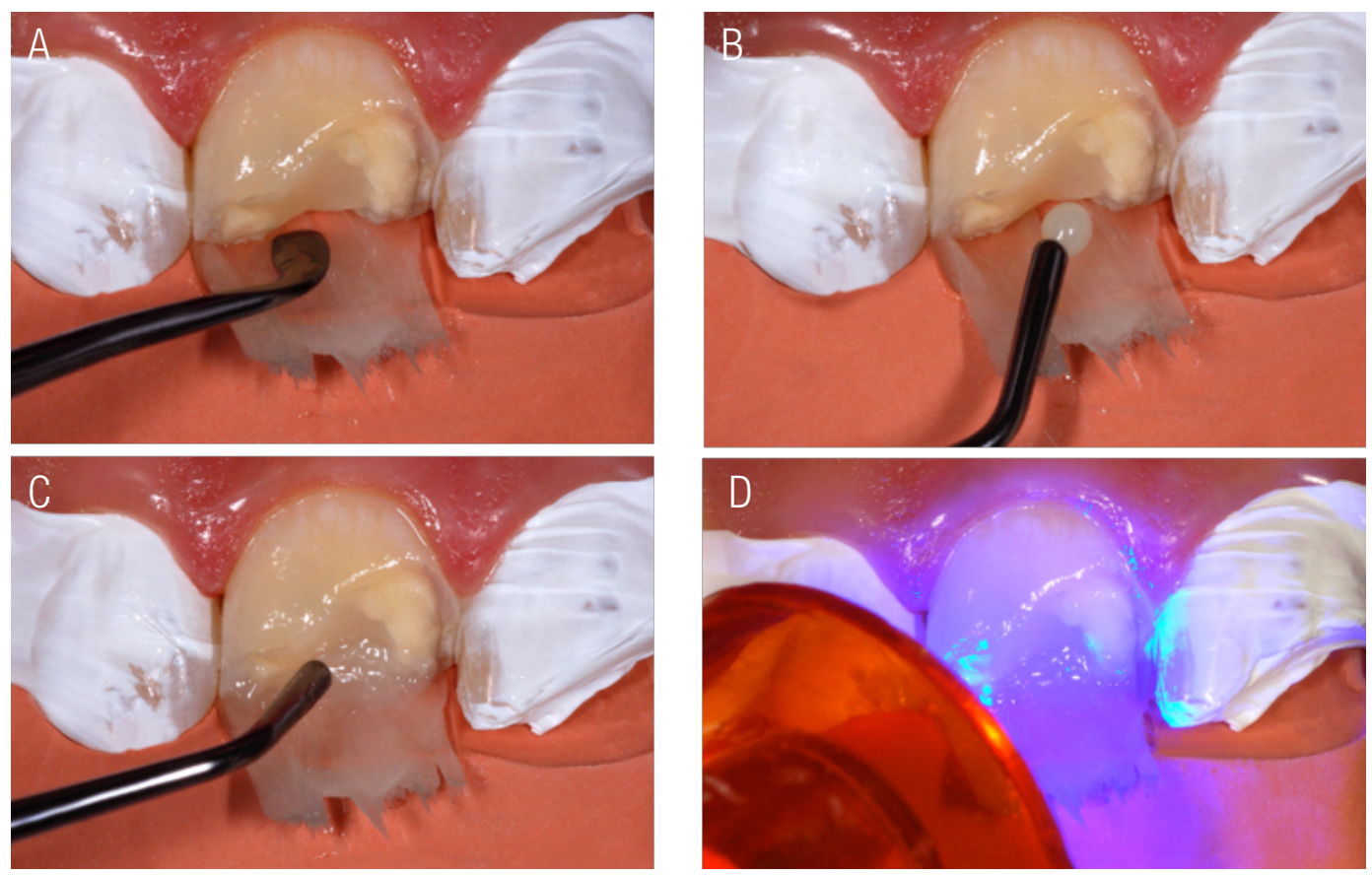

Figura 12. A a D. Aplicación de incrementos de resina compuesta para fijar el componente de material de refuerzo FRC.

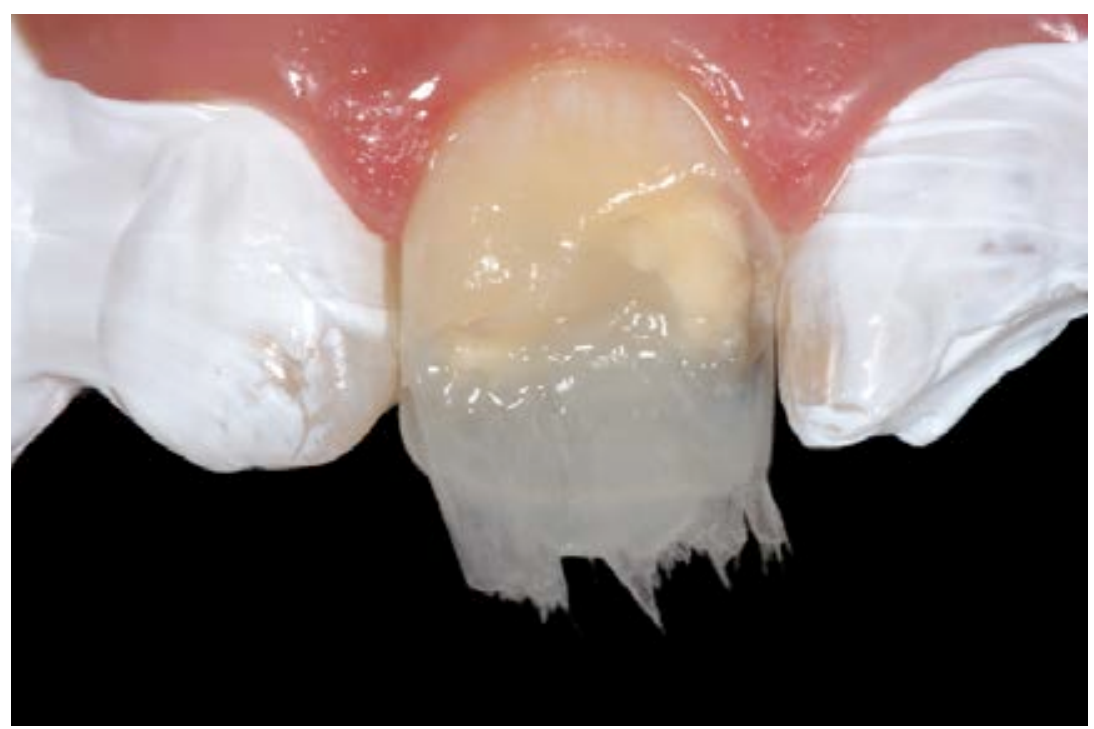

Figura 13. En complemento se observa la integración del material FRC posicionado por la resina compuesta de unión. 

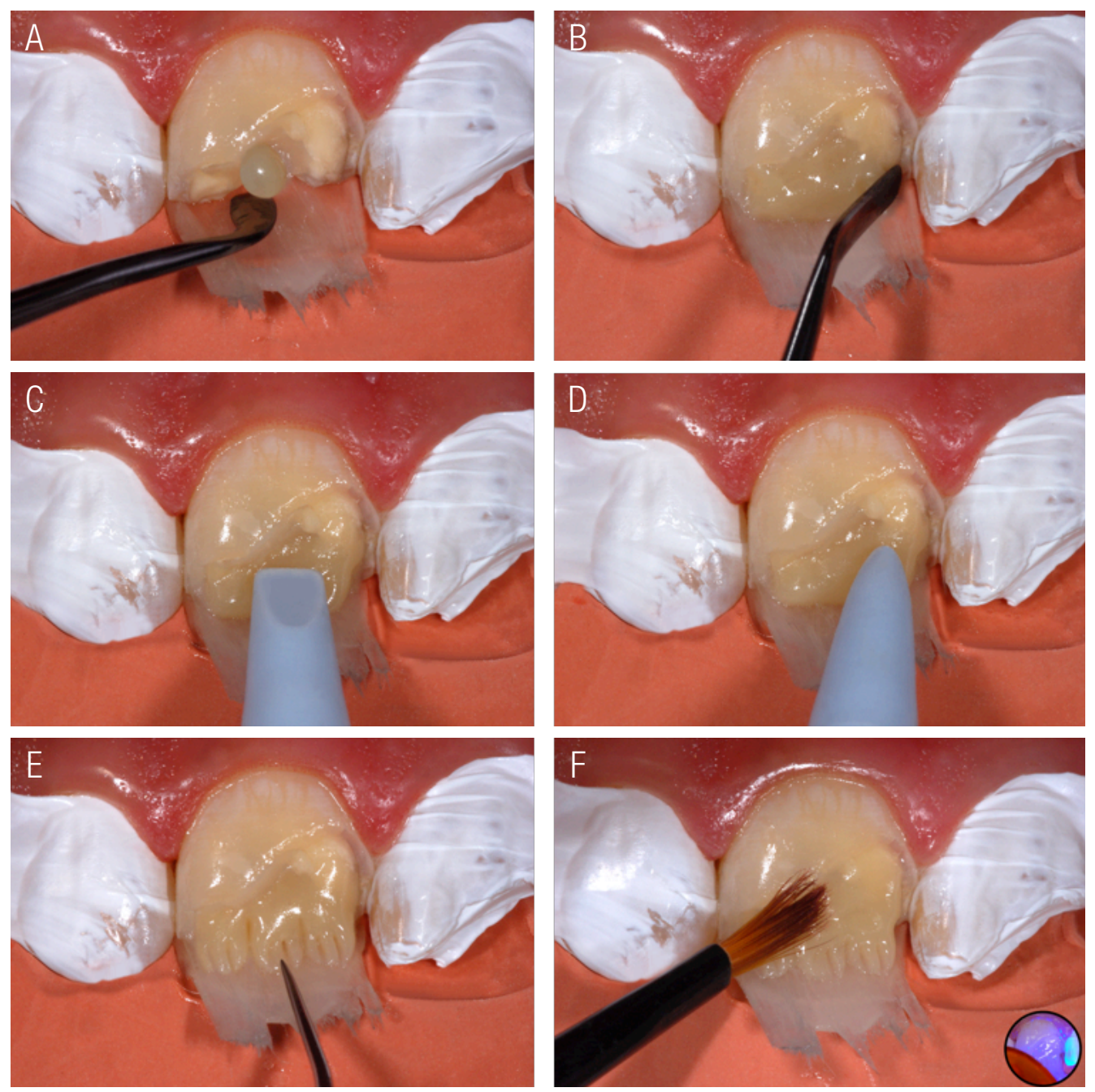

Figura 14. A a F. Obsérvese la secuencia para la confección paso a paso de la resina compuesta CIV convencional. 

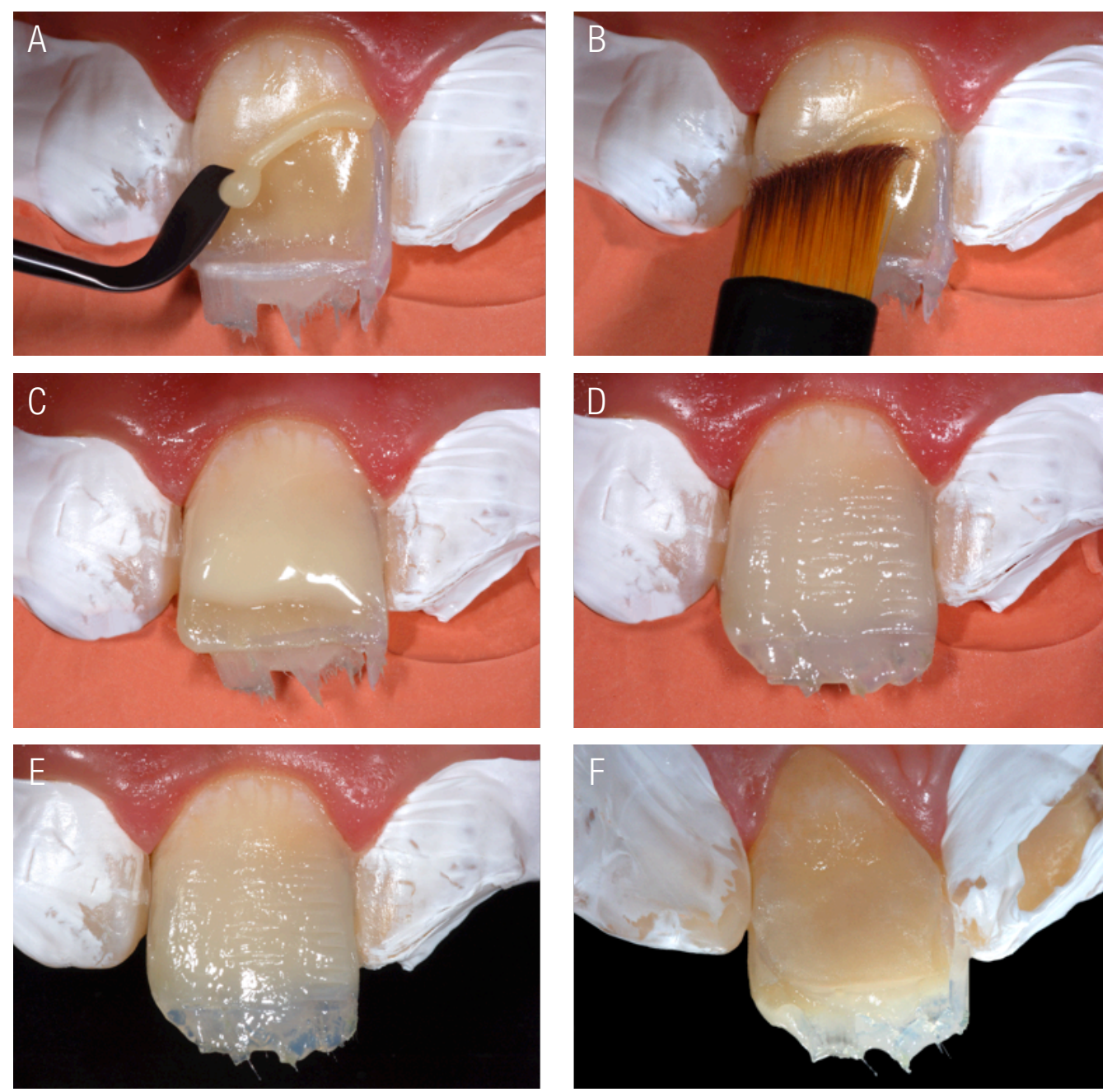

Figura 15. A a F. Se aprecian los detalles al colocar uno a uno los incrementos de resina compuesta, evidenciando el valor de cada uno de ellos.

Una vez terminada la forma de la restauración periféricamente fue realizado el desgaste, pulido y acabado de la restauración final (Figura 16).

La restauración de la pieza 1.1 fue finalizada. Así las restauraciones de las piezas dentales 2.1 y 2.2 fueron confeccionadas respetando y repitiendo el protocolo establecido para la pieza dental 1.1 (Figura 17).

El protocolo de las siguientes piezas dentales se confeccionó de la misma forma, siguiendo paso a paso cada una de las inserciones de resina compuesta para confeccionar las restauraciones híbridas con material FRC y resina compuesta (Figura 18. A a D).

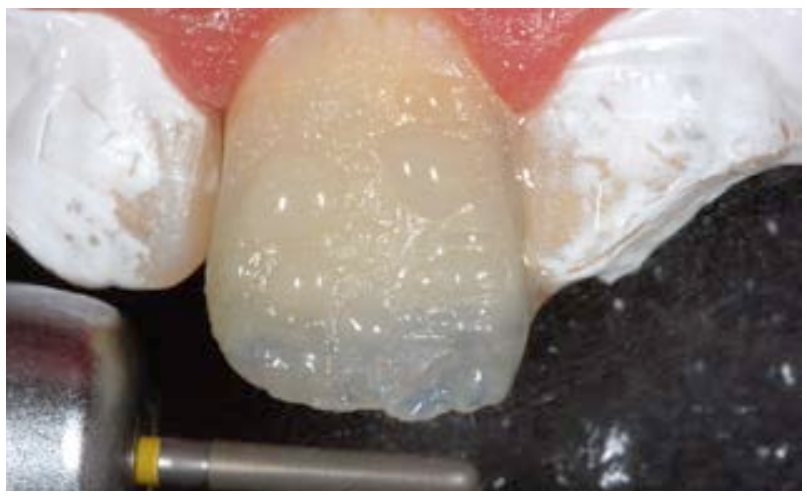

Figura 16. Observe la sobreextensión en el momento de la eliminación incisal de la pieza dental restaurada. 


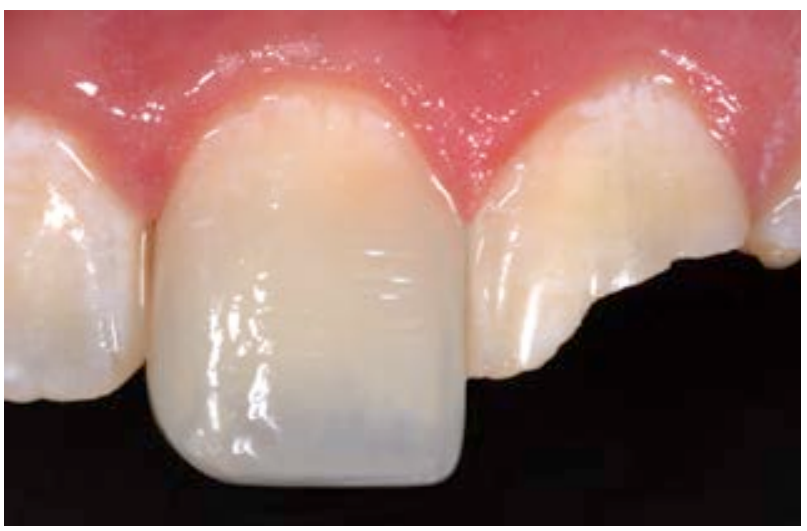

Figura 17. Restauracion final de la pieza dental 1.1.
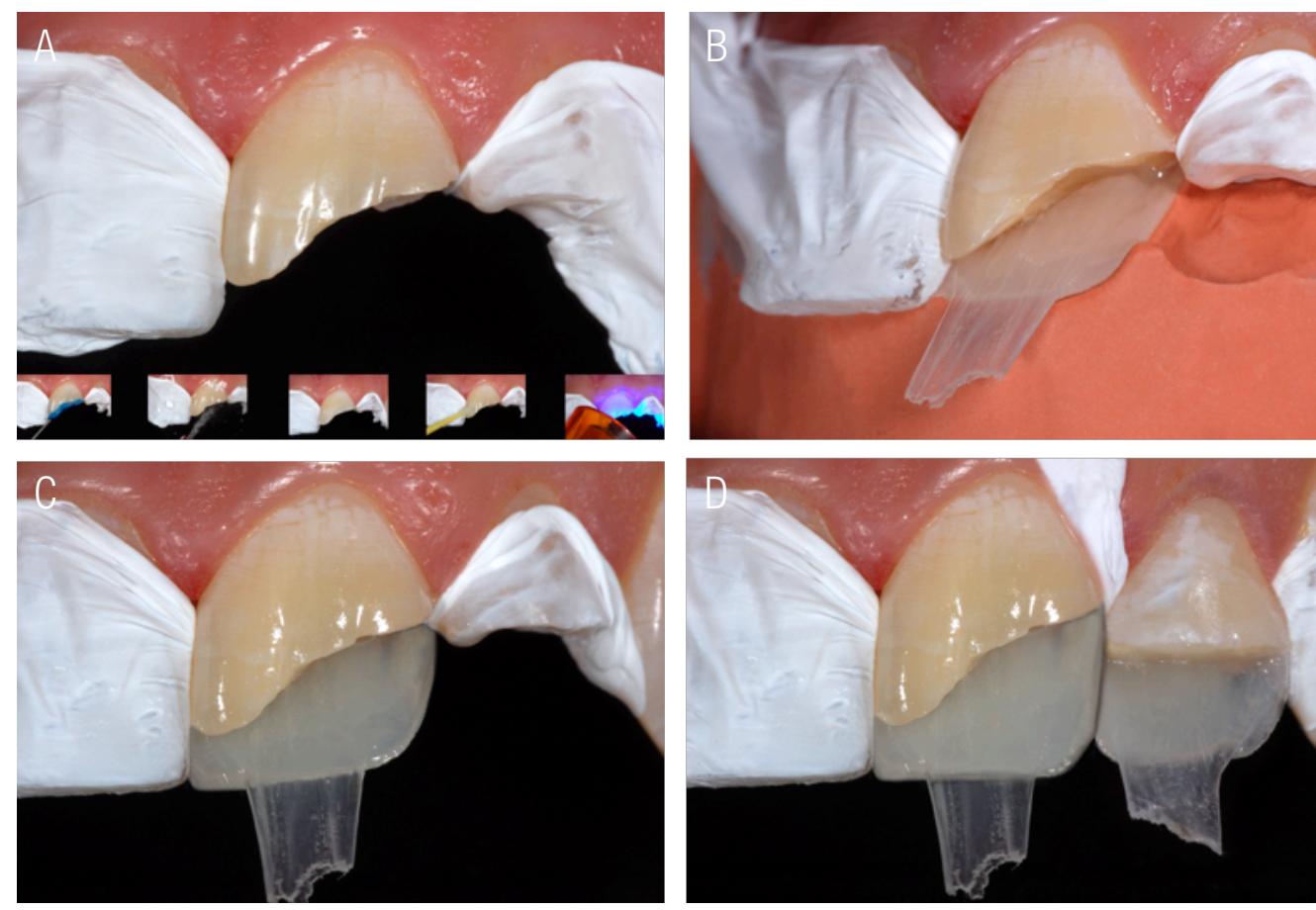

Figura 18. A a D. Secuencia de las faltantes restauraciones en las piezas 2.1 y 2.2 siguiendo el mismo protocolo restaurador. 


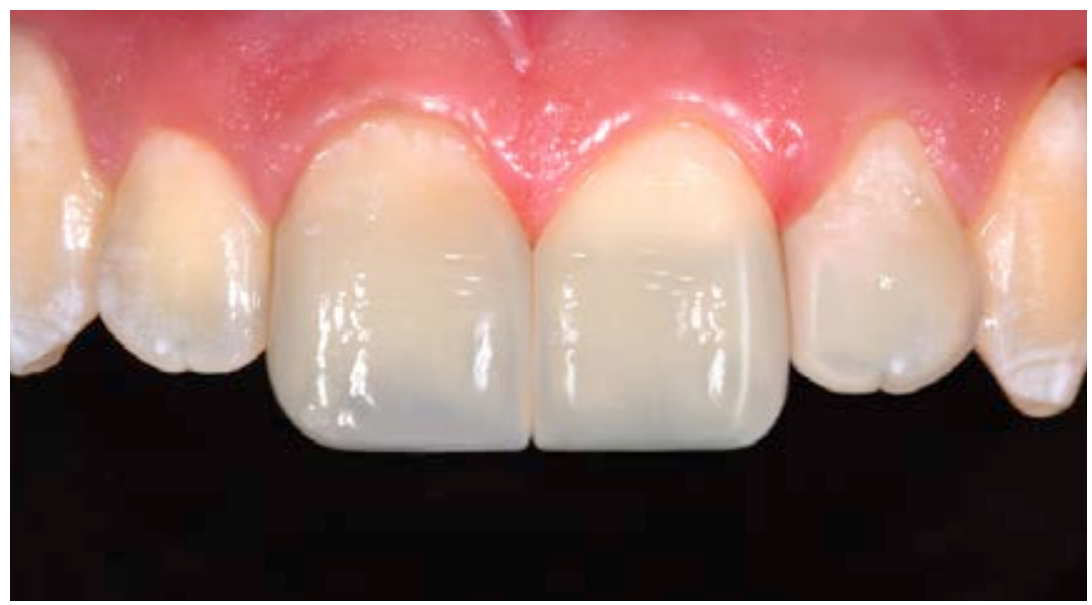

Figura 19. Restauraciones Finales. Según confección del encerado diagnóstico y como replica de la guía de silicona.

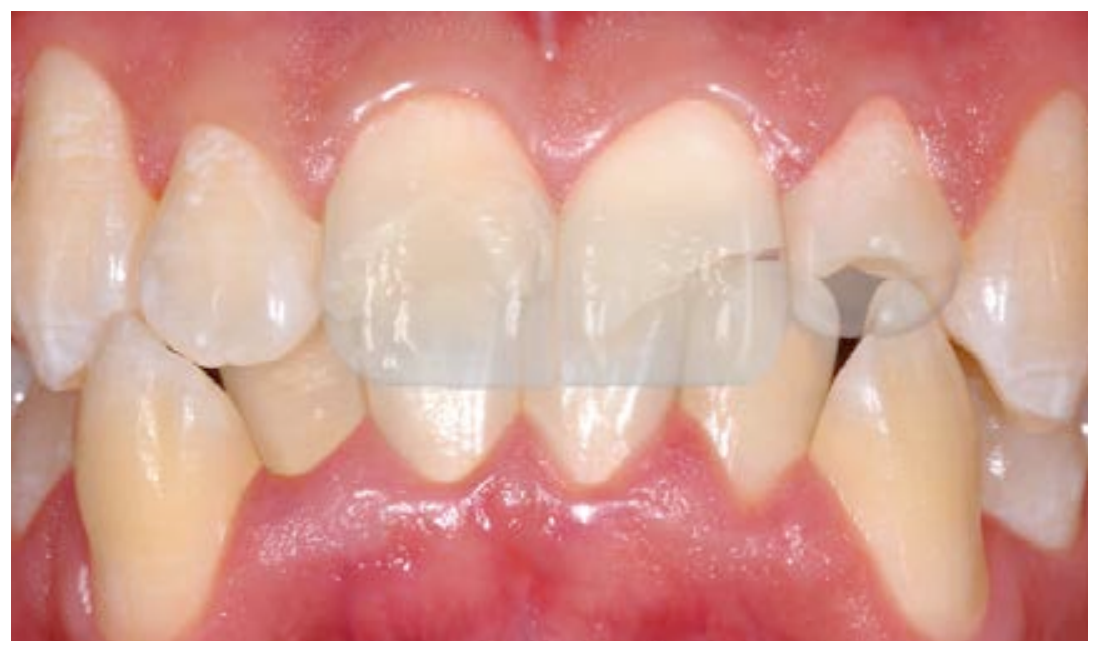

Figura 20. Restauraciones Finales en sobreposición, obsérvese la fractura franca y la restauración final confeccionada.

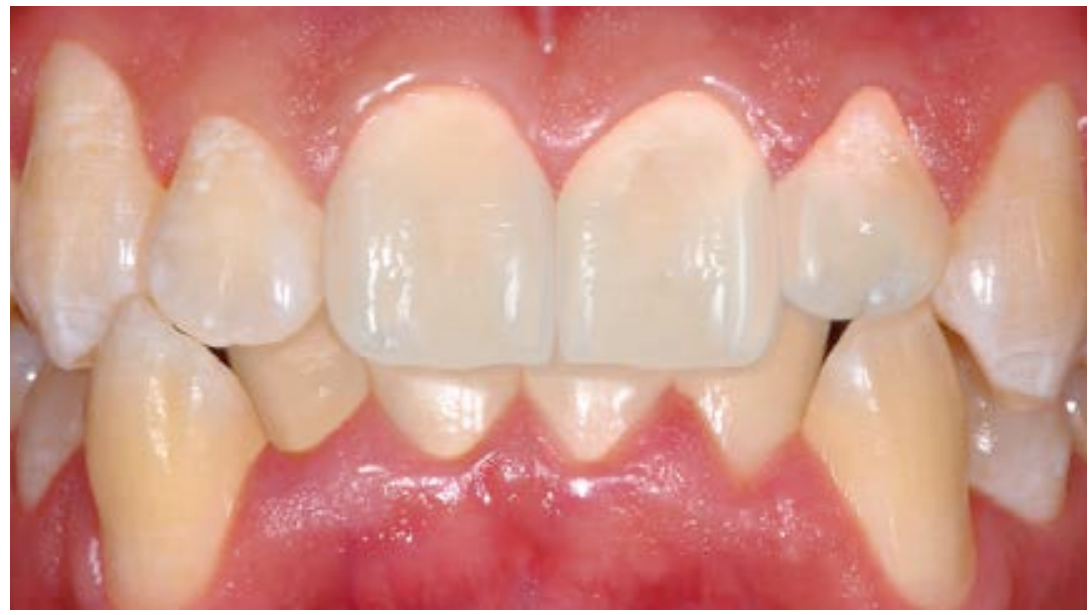

Figura 21. Restauraciones Finales. Caracterización final de las restauraciones, los rebordes incisales fueron diseñados acorde la armonía de la anatomía de sus piezas vecinas. 
CONCLUSIÓN

El enfoque del tratamiento dental, que utiliza beneficiosamente las propiedades versátiles de Ios FRC's, se denomina "enfoque de tratamiento dinámico", donde el tratamiento restaurativo y protésico comienzan con el planteamiento de una intervención mínimamente invasiva, y solo si, y si es necesario, con una prostodoncia convencionalmente más destructiva.

\section{REFERENCIAS}

1. Smith, D.C. Recent developments and prospects in dental polymer. J. Prosthet. Dent 1962; 12: 1066-1078.

2. Ladizesky, N.H. The integration of dental resins with highly drawn polyethylene fibres. Clin. Mat 1990; 6: 181-192.

3. Vallittu, P.K., Lassila, V.P. Reinforcement of acrylic resin denture base material with metal or fibre strengtheners. J. Oral Rehabil 1992; 19: 225-230.

4. Vallittu, P.K. Comparison of two different silane compounds used for improving adhesion between fibers and acrylic denture base material. J. Oral Rehabil 1993; 20 : 533-539.

5. Ladizesky, N.H., Chow, T.W., Cheng, Y.Y. Denture base reinforcement using woven polyethylene fiber. Int. J. Prosthodontic 1994; 7: 307-314.

6. Freilich, M.A., Duncan, J.P., Meiers, J.C., Goldberg, A.J. Preimpregnated, fiberreinforced prostheses. Part I. Basic rationale and complete coverage and intracoronal fixed partial denture design. Quintessence Int 1998; 29: 689-696.

7. Loose, M., Rosentritt, M., Leibrock, A., Behr, M., Handel, G. In vitro study of fracture strength and marginal adaptation of fiberreinforced-composite versus all ceramic fixed partial dentures. Eur. J. Prothodont. Rest. Dent 1998; 6: 55-62.
8. H. Miyairi, M. Nagai, and A. Muramatsu, "Studies on mechanical properties of denture base material laminated with organic fiber reinforced plastics. Part I. Basic consideration of hybrid construction," Bulletin of Tokyo Medical and Dental University Dec 1975; 22 (4): 273-280.

9. R. Seemann, M. Marincola, D. Seay, C. Perisanidis, N. Barger, and R. Ewers, "Preliminary results of fixed, fiber-reinforced resin bridges on four $4 \times 5 \mathrm{~mm}$ ultrashort implants in compromised bony sites: A pilot study," Journal of Oral and Maxillofacial Surgery 2015; 73 (4): 630-640.

10. J. Tanner, M. Tolvanen, S. Garoushi, and E. Sa ïlynoja, "Clinical Evaluation of FiberReinforced Composite Restorations in Posterior Teeth - Results of 2.5 Year Follow-up," The Open Dentistry Journal 2018; 2 (1): 476-485.

11. Vallittu, P.K. High aspect ratio fillers: fiberreinforced composites and their anisotropic properties. Dent. Mater 2014; 31: 1-7.

12. V. Cacciafesta, M. F. Sfondrini, A. Lena, A. Scribante, P. K. Vallittu, and L. V. Lassila, "Flexural strengths of fiber-reinforced composites polymerized with conventional lightcuring and additional postcuring," American Journal of Orthodontics and Dentofacial Orthopedics 2007; 132 (4): 524-527.

13. D. L. S. Foek, E. Yetkiner, and M. Ozcan, "Fatigue resistance, debonding force, and failure type of fiber-reinforced composite, polyethylene ribbon-reinforced, and braided stainless steel wire lingual retainers in vitro," The Korean Journal of Orthodontics 2013; 43 (4): 86-192.

14. O. Kumbuloglu, M. Ozcan, and A. User, "Fracture strength of direct surface-retained fixed partial dentures: Effect of fiber reinforcement versus the use of particulate filler composites only," Dental Materials 2008; 27 (2):195-202.

15. A. Agrawal and K. Mala, "An in vitro comparative evaluation of physical properties 
of four different types of core materials," Journal of Conservative Dentistry 2014; 17 (3): 230-233.

16. J. Bijelic-Donova, S. Garoushi, L. V. J. Lassila, and P. K. Vallittu, "Oxygen inhibition layer of composite resins: effects of layer thickness and surface layer treatment on the interlayer bond strength," European Journal of Oral Sciences 2015; 123 (1): 53-60.

17. B. Akalin-Evren, Y. Kulak-Ozkan, M. Ozcan, and T. Kadir, "Candida albicans adhesion on reinforced poly-methylmethacrylate denture resin: Effect of fibre architecture and exposure to saliva," Gerodontology 2014; 31 (3) 194-201.

18. M. F. Sfondrini, V. Cacciafesta, and A. Scribante, "Shear bond strength of fibrereinforced composite nets using two different adhesive systems," European Journal of Orthodontics 2011; 33 (1): 66-70.

19. A. Scribante, V. Cacciafesta, and M. F. Sfondrini, "Effect of various adhesive systems on the shear bond strength of fiberreinforced composite," American Journal of Orthodontics and Dentofacial Orthopedics 2006; 130 (2): 224-227.

20. A. Sharma, F. Samadi, J. Jaiswal, S. Saha, and N. Marwah, "A Comparative Evaluation of Effect of Different Chemical Solvents on the Shear Bond Strength of Glass Fiber reinforced Post to Core Material," International Journal of Clinical Pediatric Dentistry 2014; 7: 192-196.

21. A. I. Karaman, N. Kir, and S. Belli, "Four applications of reinforced polyethylene fiber material in orthodontic practice," American Journal of Orthodontics and Dentofacial Orthopedics 2002; 21 (6): 650-654.

22. S. Garoushi and S. Patil, "Single Visit Replacement of Maxillary Canine using Fiber-reinforced Composite Resin," The
Journal of Contemporary Dental Practice, 2013: 25-129.

23. S. Murali Mohan, E. Mahesh Gowda, and M. P. Shashidhar, "Clinical evaluation of the fiber post and direct composite resin restoration for fixed single crowns on endodontically treated teeth," Medical Journal Armed Forces India 2015; 71 (3):259-264.

24. Davidson, C.L. Principles of Adhesion. In: Dondi dall' Orologio, G., Fuzzi, M., Prati, C. (Eds.), Adhesion in Restorative Dentistry. Tipolitografia Valbonesi, Forli, Italy; 1996: 1-4.

25. da Silva, L.F.M., Ochsner, A., Adams, R.D. Introduction to adhesive bonding technology. Handbook of Adhesion Technology. Springer, Heidelberg, 2011: 1-7.

26. Ausiello, O., Apicella, A., Davidson, C. Effect of adhesive layer properties on the stress distribution in composite restorations:a 3D finite element analysis. Dent. Mater 2002; 18: 295-303

27. A.S.Khan, M.T.Azam, M.Khan, S.A.Mian, I.U.Rehman, Anupdateonglassfiber dental restorative composites: a systematic review, Mater. Sci. Eng. C-Mater. Biol. (2015); Appl. 47: 26-39.

28. P. Benito, R. Trushkowsky, K. Magid, S. David, Fiber-Reinforced framework in conjunction with porcelain veneers for the esthetic replacement of a congenitally missing maxillary lateral incisor: a case study, Oper. Dent (2012); 37: 576-583.

29. M. Zarow, C.S. Paisley, J. Krupinski, P.A. Brunton, Fiber-reinforced composite fixed dental prostheses: two clinical reports, Quintessence Int 2010; 41: 471- 477.

30. C.Monaco,Aclinicalcasereportonindirect,po steriorthree-unitresin-bonded FRC FPD, J. Adhes. Dent 2012; 14: 479-483.

31. F.J. Burke, Resin-retained bridges: fibrereinforced versus metal, Dent. Update 2008; $35: 24-26 / 521-522$. 